\title{
Newspaper Reports on BSE around the Time of the Japan-US Trade Conflicts: Content Analysis of Japanese and US Dailies from 2002 to 2006
}

\author{
Hajime Sato ${ }^{*}$, Rose G. Campbell ${ }^{2}$ \\ ${ }^{1}$ Department of Health Policy and Technology Assessment, National Institute of Public Health, Wako, Japan \\ ${ }^{2}$ Strategic Communication Department, College of Communication, Butler University, Indianapolis, USA \\ Email: ${ }^{*}$ hsato-tky@umin.ac.jp
}

Received 25 January 2014; revised 1 March 2014; accepted 10 March 2014

Copyright (C) 2014 by authors and Scientific Research Publishing Inc.

This work is licensed under the Creative Commons Attribution International License (CC BY). http://creativecommons.org/licenses/by/4.0/

(c) (i) Open Access

\begin{abstract}
Mass media can affect how people understand and react to particular health risks. Reporting of health risks during the international trade disputes, resulting from the difference in safety regulations, therefore can play a pivotal role in resolving them. This study compared the newspaper reports on BSE-related events in major national dailies between Japan and the US around the period when BSE-infected cattle were discovered in the US and the import of US beef products was banned (between December 2002 and November 2006). During the study period, the number of BSE-related newspaper articles increased in both the US and Japan, but the visibility of the issue was more prominent and persistent in Japan than in the US. Geographically, most of the articles had a domestic focus, but they also reported the news of each trade partner. After the discovery of BSE cattle in the US, articles of commerce and trade issues were dominant in Japan, while the incidence of BSE, agriculture, and trade dominated in the US. Overall, the US-based newspapers carried more advocacy articles than the Japanese ones. In Japan, calls for stronger domestic policy decreased, but those for stronger foreign policy increased slightly. Meanwhile, in the US, calls for a stronger domestic policy increased slightly whereas those for weaker foreign policy dropped-both only temporarily. The major rationale for policy advocacy was the economy and health in both Japan and the US. However, the balance of competing policy objectives and the rational acceptance of BSE risks were argued more in the US papers than in the Japanese ones. In conclusion, during the BSE-related dispute on health and trade, the visibility and faces of the issues in newspapers differed between Japan and the US. Acceptance of BSE-related risks was argued differently, and those differences reflected and affected the public's perception of BSE issues, the related safety policies by the governments, and the configuration of social interests in each country. The differ${ }^{*}$ Corresponding author.


ences evident in the media could serve as a vehicle for reappraising the existing policies as well as the possible international harmonization of risk management policies.

\title{
Keywords
}

\author{
Mass Media; Newspapers; BSE; Risk Communications; Japan; US
}

\section{Introduction}

Mass media can affect how people understand and react to particular health risks (Goodel, 1987). Media content is the most important source of information for most people. News reports help shape the public definition of health risks and risk-related events by selectively attributing to them specific details or particulars. Furthermore, media coverage is sometimes observed by politicians as a crucial instance of public opinion, as it serves as an important indicator of public opinion (Kleinschmit \& Krott, 2008). It could thus have the ability to set the public agenda, prime audiences to ascribe differing degrees of salience to available information, and provide frames to understand risk events (Kim, Scheufele, \& Shanahan, 2002). The role of the mass media is therefore central to socio-political processes regarding health crises (Cotte \& Beck, 1998). From the standpoint that the media affects and reflects the social process of risk events, the examination of media reports of health risks would help understand how a given health risk emerges and is managed in society.

Bovine spongiform encephalopathy (BSE), also known as mad cow disease, is a neurological infectious disease affecting cows that was first reported in the UK in 1986. The possibility of its human transmission became known in the mid 1990s, when many European countries started to experience epidemics of BSE cases. People blamed the risk management policies of their own governments and those of the others. By the turn of the century, most countries-not confined to those in Europe-had introduced certain sets of BSE prevention measures, sometimes by setting up their own safety standards and procedures. The discovery of BSE cattle came relatively late in the US and Japan: The first case in Japan was reported in 2001 and in the US in 2003. Immediately upon the discovery of the US case, a ban on US beef imports was implemented in Japan. In the two years after that, the Japanese and US governments negotiated safety measures and standards for beef products, reappraised and adjusted their BSE-related policies, and eventually agreed to resume trade (US International Trade Commission, 2008).

The mass media conveyed many news reports on BSE in Japan and the US, especially during these years. This article aims to examine the visibility and faces of BSE issues as they appeared in newspaper articles in Japan and the US as well as compare how the BSE issue was presented to the public during this period. An analysis of the quantity and content will disclose how BSE incidents, the related health risks, and social effects were portrayed and what policy choices (aversion and acceptance of risks, as regarded rationale) were considered appropriate. The paper then discusses what roles the mass media played in (re-)appraising BSE-related safety standards and regulations and harmonizing them between the two countries. Their implications for future health risk management are considered.

\section{Materials and Methods}

\subsection{Materials}

The first BSE-infected cattle was reported in December 2003 in the US, and the ban on US beef was immediately introduced in Japan. In the following two years, the US federal government introduced a set of policy measures for food safety and trade promotion, and a series of negotiations were held between the US and Japanese governments. The trade ban was then lifted in December 2005. Our study targeted a four-year period, from December 2002 (a year before the first BSE-infected cattle was discovered in the US) and ending November 2006 (a year after the trade of US beef resumed).

Two Japanese and US national dailies were selected for study: The Yomiuri Shimbun and The Asahi Shimbun in Japan and The New York Times and The Washington Post in the US. These papers had, at the time, the largest and second largest numbers of circulation, respectively, in Japan and the US. Articles were searched and col- 
lected from these papers, using the keywords BSE (Bovine spongiform encephalopathy) and mad cow disease. In addition, articles with other related keywords, such as (variant-)Creutzfeldt-Jakob disease (vCJD), safety of beef (products), and ban on beef trade, were searched for and checked individually to determine if they reported or discussed BSE-related events; those that did were included for analyses.

\subsection{Methods}

Counting and coding of articles. First, we focused our analysis on the number of articles, ignoring their word counts, placement, and font sizes. Second, all included articles were coded and counted for article content/frame. A frame denotes here a way of packaging and positioning an issue so that it conveys a certain meaning (Chapman \& Lupton, 1994; Wallack \& Dorfman, 1996). Coders in both countries used a coding system based on the framework developed similar to those previously employed (Campbell \& Sato, 2009; Smith et al., 2005). Issue frame elements for coding, which were derived from the preliminary qualitative interpretation of articles/policy documents, comprised geographic focus (US, Japan, and other countries), and topic categories (BSE incidents, biomedical effects and risks to humans, vCJD, effects on commerce and related policies, agricultural effects and related policies, effects on international trade and related policies). As there could be multiple categories in each article, more than one frame category could be coded per article.

Third, the tone or slant (i.e., advocacy orientation) of the articles was analyzed in terms of their advocacy attributes. An article was assessed as positive when it argued for stronger safety measures/policies and negative when it contained arguments for weaker measures/policies. The article was designated neutral if it did not clearly argue for either stronger or weaker policies, was ambiguous, or had relatively equal amounts of orientations. Finally, the argumentative bases (policy discussion contexts) of articles, if any, were coded using the categories of health, economy, balance of different policy objectives, and (rational) acceptance of health risks. All the coding was done independently by two pre-trained coders, yielding a reliability rate of $83 \%$, which was considered within the acceptance levels for study (Miles\& Huberman, 1994).

Statistical analysis. The overall study period consisted of three distinct sub-periods (hereby denoted as periods): Period I (the period preceding the trade ban period on US beef products), Period II (the period of the trade ban, triggered by the discovery of BSE cases in the US), and Period III (the period following the trade resumption). After obtaining the descriptive statistics (numbers, means, and standard deviations), a comparison was made between adjacent periods in each country as well as between Japan and the US in the given study period. Relationships of advocacy orientation with rationale were examined, using multi-nominal logistic regression analysis. In the model, a neutral orientation was chosen as the base outcome, and the coefficients (relative risk ratios) of the presence of each rationale for the article orientation (positive or negative) were estimated (Treiman, 1994). Statistical analyses were conducted using Stata Special Edition, version 12 (StataCorp, College Station, Texas, USA).

\section{Brief History of BSE in Japan and the US}

\subsection{BSE in Japan}

In 1986, when the BSE cases were reported in the UK, the import of UK beef products, including meat and bone meal (MBM), was stopped-first voluntarily and then by the order of the Ministry of Agriculture, Forestry and Fisheries (MAFF). In 1997, when the spread of BSE to humans in the form of vCJD was confirmed, BSE became classified as a notifiable animal disease. In response to the widespread incidents of BSE in Europe, the import of bovine brains and spinal nerves was voluntarily stopped, and in 2000 the MAFF banned the use of MBM for animal feed. In the following year, the MHW banned the import of European beef products, and the MAFF started a surveillance program to determine how many cows older than 24 months had abnormal neurological symptoms. Meanwhile, the domestic beef industry launched its "Safe Domestic Beef" campaign to reassure consumers and differentiate its products from imported ones.

The first BSE case in Japan was confirmed in August 2001. The MAFF immediately announced this fact and stopped the shipment of beef from the farm concerned. The MAFF soon conducted an emergency survey targeting all cattle and tightened BSE screening so that cows older than 24 months that showed abnormal neurological signs or were generally ill, as well as all cows older than 30 months, were tested for BSE (the age limit of 24 months was adopted because the tests lacked the technology to detect the BSE prion reliably). Thorough testing 
of cattle, regardless of age, was introduced along with a cattle tracking system to reassure consumers as exact cow ages were hard to determine precisely. Furthermore, in 2003, the Food Safety Commission (FSC) was created under the Prime Minister's office, and the MAFF was reformed so as to separate the consumer safety department from the department for industrial development. The beef market and consumer trust recovered only after the government introduced these measures.

When BSE cases were first reported in the US and Canada in December 2003, a ban on imports of cattle and beef products from these countries was immediately enacted. As this ban soon became a trade issue, the US-Japan BSE Working Group was created to address the issue, and the differences in how the two countries managed the risks of BSE were placed on the policy agenda. The creation of the Beef Export Verification (BEV) Program by the USDA was then decided and approved by both parties, which aimed to specify product requirements for beef exported to Japan, such as the age limit on beef to be exported (only beef items derived from bovine animals verified to be 20 months of age or younger), the removal of SRM, and the inclusion of cattle tracking (traceability), as well as to verify the compliance of US beef exporters with these requirements.

Triggered by this dispute, in 2004, the FSC started to reassess BSE-related policies in Japan. It concluded that the current complete cattle testing was hardly meaningful as the BSE prions could not be detected and that testing cows older than 30 months, a cattle tracking system, SRM removal, and a ban on the use of MBM were sufficient to decrease the risk of vCJD. Consulted by the MHLW and the MAFF, the FSC further concluded that the scope of BSE testing could be safely reduced from all cattle (Japanese standards at that time) to cattle over 20 months old (proposed by US trade representatives). The draft of the FSC report was released in December 2004 and finalized in May 2005. In October, after the required target of BSE testing was reduced, the US and Japanese governments announced that bilateral trade in beef should be resumed based on the mutually approved conditions. The FSC also released its report that the difference in risk between domestic beef and US beef was minimal (Sato, 2010).

On December 12, 2005, the Japanese government decided to lift the import ban, although only beef from cattle younger than 20 months could be exported. However, in January 2006, a calf vertebra-prohibited by trade standards-was found in an airborne package from the US, and the import approval was immediately stopped. In March, the USDA submitted its report to the Japanese government, which was shortly made public. The USDA issued directives and notices on the BEV Program to ensure compliance. Following Japan's review of the eligibility of US slaughter facilities to export to Japan, the market reopened in July 2006. The US cattle and beef industries repeatedly complained about Japan's safety regulations, particularly the 20-month age limit (the international standard was 30 months) and the strict monitoring of cattle ages.

\subsection{BSE in the United States}

Following the 1985 report of BSE in the UK, an inter-agency working group was established by the US government in 1988 to study BSE. As a firewall, the United States Department of Agriculture (USDA) banned all imports of live cattle and other ruminants from the countries identified as presenting a high risk for BSE. In 1990, the USDA started its own BSE testing program, and 40 cattle brains were tested. When the Office International des Epizooties (OIE) created international standards for animal surveillance, the USDA instituted its own program in 1991 at a higher level. In 1997, the government extended the import ban on live cattle, cattle feed, and beef products to include all of Europe. The USDA for the first time banned the use of mammalian protein for animal feed.

The BSE testing program expanded to nearly 20,000 cattle brains in 2002, although this still amounted to less than $1 \%$ of the cows slaughtered each year, and only cows that were disoriented or presented suspicious neurological symptoms were tested. The government reaffirmed its import restrictions and allowed the import of beef products only if the country of origin had been implementing adequate BSE controls since 1989 (Canada was the first one). When a BSE case was confirmed in Canada in May 2003, the US immediately reinstituted the ban on the import of Canadian beef and cattle. The Canadian government criticized this ban as Canadian and US cattle were commingled. After three months, the import of Canadian beef products gradually resumed, despite the oppositions of US agricultural and meat industries.

The first BSE case in the US was confirmed on December 23, 2003. Although suspect cows were slaughtered and marketed before BSE test results were known, USDA officials stated that infectious animal parts such as the brain and spinal cord were removed before processing and, therefore, the beef products being shipped were not 
as risky. Soon thereafter, the USDA ordered the removal of SRMs at the slaughterhouse from cows older than 30 months. In addition, it implemented new procedures to verify cows' ages, banned the use of advanced meat recovery and air injections, and introduced a test-and-hold rule for non-ambulatory cows. Early in 2004, the USDA concluded that it had been scientifically established that only cows over 30 months old were at risk of BSE; thus, it adopted a rapid screening procedure, supplemented by an immuno-histochemistry test for inconclusive cases. It also launched a 12-to 18-month screening program to test a high percentage of downer cows. When a second BSE case was found in June 2005, the Western blot test was further added to these latter cases.

Some people in agriculture and related businesses were concerned that US policy would respond to consumers' fears rather than making science-based choices. Notably among them, the National Cattlemen's Beef Association launched crisis campaigns that were developed based on consumer research after European BSE incidents. They included an e-conference with media representatives within 15 minutes of the breaking news as well as a website as a source of credible information for media, policymakers, beef export markets, and consumers. Front groups for industry, such as the Center for Consumer Freedom (CCF), made headlines in support of the food industry to criticize the possible BSE hype. The BSE issue became seen as a success story of industry crisis management in the US (Campbell \& Sato, 2010).

Immediately after the discovery of BSE cattle in the US, many countries banned the import of US beef, including Japan. Its economic effects on the beef trade were duly on a serious scale. Until 2003, before the discovery of BSE cattle in the US, Japan had been the largest foreign market for US beef. For Japan, the US was at the time the second largest foreign supplier of beef, behind Australia, and more than half of the Japanese beef supply came from imports (Obara, McConnel, \& Dyck, 2010). Thus, in the US, the resumption of beef trade to Japan became an important agenda for agricultural interests and the Department of Agriculture, who vigorously worked together to reopen the Japanese market by developing the Export Verification program, targeting Japan. They searched for and negotiated on safety standards acceptable to the government and market of Japan and, at the same time, continuously pressured Japan to change its beef import restrictions to be a more lenient and more compatible with US domestic safety standards.

\section{Results}

Monthly average numbers of newspaper articles on BSE (two dailies for each country) are shown in Table 1, along with their geographic focuses and topic categories. The Japanese papers carried significantly more articles than the US papers throughout the three periods. Compared with the preceding periods, the numbers of articles increased in Period 2, then decreased in Period 3 in both countries (Figure 1). These changes were statistically significant only in Japan.

Geographically, approximately $90 \%$ of articles, on average, had a domestic focus. In Japan, articles carrying US topics increased significantly in Period 2 (4.1\% to 29.9\%) and persisted in the following period. Meanwhile, in the US newspapers, articles reporting on Japan gradually increased from $14.1 \%$ in Period 1 to $34.9 \%$ in Period 3. Those focusing on countries other than the US and Japan continuously decreased.

With regard to the topic categories, articles on commerce comprised approximately $55 \%$ to $62 \%$ of the articles in Japan throughout the study periods. Although those on agriculture quickly decreased $(30.0 \%, 9.9 \%$, 5.8\%), articles on trade remarkably increased in Period 2 (from 10.5\% to 34.3\%), when a BSE cattle was found in the US and the import ban was introduced. They again increased in Period 3 (47.9\%). The decrease in the number of reports on agriculture in Periods 2 and 3 and the increase of those on trade in those same periods were statistically significant.

On the other hand, topic categories frequently reported by the US papers include the incidence of BSE cases (61.2\%, 66.2\%, and 53.4\% in each period, respectively), agriculture (60.5\%, $44.8 \%$, and $41.1 \%)$, and trade (51.7\%, 51.6\%, and 54.7\%). Reports on commerce accounted for approximately $30 \%$ of the articles throughout the study periods. Changes in all the topic categories of US papers between adjacent periods were not statistically significant.

Policy advocacy observed in newspaper articles in each period is shown in Table 2. In Japan, calls for stronger domestic policy decreased significantly in Periods 2 and 3 (from $7.3 \%$ in Period 1 to $4.1 \%$ and $4.1 \%$ in the following periods), while those for weaker policy remained unchanged between $2.3 \%$ and $2.7 \%$. Calls for stronger foreign policy increased in those periods (from $0.2 \%$ to $3.9 \%$ and $2.6 \%$ ). In the US, on the other hand, calls for stronger domestic policy slightly increased temporarily in Period 2 (from 12.7\% to 18.5\%), and then 
Table 1. Numbers and topics of BSE articles.

\begin{tabular}{|c|c|c|c|c|c|c|c|c|c|c|c|c|c|}
\hline & & \multicolumn{4}{|c|}{ Dec 2002-Nov 2003} & \multicolumn{4}{|c|}{ Dec 2003-Nov 2005} & \multicolumn{4}{|c|}{ Dec 2005-Nov 2006} \\
\hline & & mean & \pm & sd & $p$ & mean & \pm & sd & $p$ & mean & \pm & sd & $p$ \\
\hline \multicolumn{14}{|c|}{ Number of articles (n/month) } \\
\hline JP papers & & 48.5 & \pm & 19.2 & $* * *$ & 92.8 & \pm & 43.1 & ***, \#\# & 60.3 & \pm & 29.4 & $* * *$, \# \\
\hline US papers & & 3.8 & \pm & 4.3 & & 16.2 & \pm & 22.3 & & 6.8 & \pm & 3.1 & \\
\hline \multicolumn{14}{|c|}{ Geographic focus (\%) } \\
\hline \multirow[t]{3}{*}{ JP papers } & US topics & 4.1 & \pm & 3.4 & & 29.9 & \pm & 13.0 & \#\#\# & 25.9 & \pm & 15.8 & \\
\hline & Japan topics & 97.3 & \pm & 2.2 & $* * *$ & 88.2 & \pm & 7.9 & $* * *$, \#\#\# & 93.5 & \pm & 4.7 & $* * *$, \# \\
\hline & Other countries & 7.8 & \pm & 4.6 & & 6.3 & \pm & 4.8 & & 6.0 & \pm & 4.4 & \\
\hline \multirow[t]{3}{*}{ US papers } & US topics & 88.3 & \pm & 17.7 & $* * *$ & 87.7 & \pm & 18.0 & $* * *$ & 94.9 & \pm & 9.9 & $* * *$ \\
\hline & Japan topics & 14.1 & \pm & 19.2 & & 19.7 & \pm & 21.4 & & 34.9 & \pm & 33.2 & \\
\hline & Other countries & 68.6 & \pm & 39.0 & $* * *$ & 42.2 & \pm & 26.1 & $* * *, \#$ & 32.9 & \pm & 27.7 & $* * *$ \\
\hline \multicolumn{14}{|c|}{ Topic categories (\%) } \\
\hline \multirow[t]{5}{*}{ JP papers } & Incidents & 7.1 & \pm & 8.9 & & 5.0 & \pm & 4.8 & & 2.8 & \pm & 2.7 & \\
\hline & Biomedical effects & 12.5 & \pm & 10.0 & & 7.7 & \pm & 4.4 & & 3.0 & \pm & 2.7 & \#\# \\
\hline & Commerce & 60.6 & \pm & 12.8 & * & 61.9 & \pm & 13.4 & $* * *$ & 55.6 & \pm & 20.5 & $* *$ \\
\hline & Agriculture & 30.0 & \pm & 18.5 & & 9.9 & \pm & 4.8 & \#\#\# & 5.8 & \pm & 4.3 & $\#$ \\
\hline & Trade & 30.0 & \pm & 18.5 & & 9.9 & \pm & 4.8 & \#\#\# & 5.8 & \pm & 4.3 & $\#$ \\
\hline \multirow[t]{5}{*}{ US papers } & Incidents & 61.2 & \pm & 37.3 & $* * *$ & 66.2 & \pm & 17.5 & $* * *$ & 53.4 & \pm & 20.1 & $* * *$ \\
\hline & Biomedical effects & 23.6 & \pm & 38.9 & & 18.4 & \pm & 15.1 & $* *$ & 16.5 & \pm & 22.9 & \\
\hline & Commerce & 35.9 & \pm & 29.7 & & 31.6 & \pm & 15.3 & & 29.2 & \pm & 18.7 & \\
\hline & Agriculture & 60.5 & \pm & 42.3 & * & 44.8 & \pm & 20.6 & $* * *$ & 41.1 & \pm & 19.8 & $* * *$ \\
\hline & Trade & 60.5 & \pm & 42.3 & $*$ & 44.8 & \pm & 20.6 & $* * *$ & 41.1 & \pm & 19.8 & $* * *$ \\
\hline
\end{tabular}

Statistical significance for differences between Japanese and US papers in the same periods: $*:<0.05, * *:<0.01, * * *:<0.001$.

Statistical significance for differences between two periods (change from the preceding period) in a given country: \#: $<0.05, \# \#:<0.01, \# \#$ : $<0.001$.

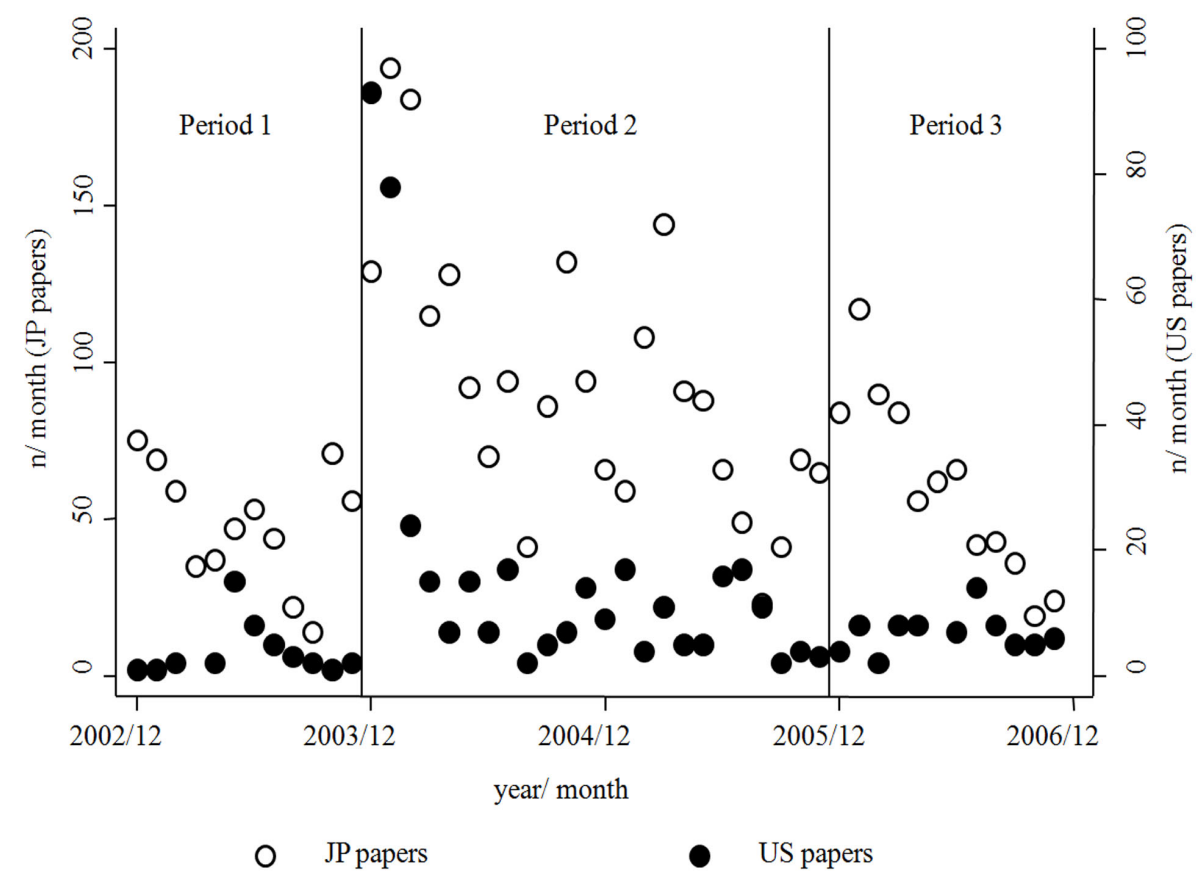

Figure 1. Number of BSE-related newspaper articles in Japan and the US.

decreased in Period 3 (14.2\%; those changes were not statistically significant). Correspondingly, calls for weaker domestic policy dropped in Period 2 (from 10.2\% to 1.6\%), and then returned to the previous level in Period 3 (9.4\%). Although calls for stronger foreign policy remained unchanged (3.9\% to 4.2\%), those for weaker foreign policy dropped temporarily in Period 2. Overall, the US papers carried more advocacy articles than the Japanese 
Table 2. Policy advocacy and its rationale for BSE articles

\begin{tabular}{|c|c|c|c|c|c|c|c|c|c|c|c|c|c|c|}
\hline & & & \multicolumn{4}{|c|}{ Dec 2002-Nov 2003} & \multicolumn{4}{|c|}{ Dec 2003-Nov 2005} & \multicolumn{4}{|c|}{ Dec 2005-Nov 2006} \\
\hline & & & mean & \pm & sd & $p$ & mean & \pm & sd & $p$ & mean & \pm & sd & $p$ \\
\hline \multicolumn{15}{|c|}{ Policy advocacy (\%) } \\
\hline \multirow[t]{4}{*}{ JP papers } & Domestic & Positive & 7.3 & \pm & 4.3 & & 4.1 & \pm & 2.5 & $\# \#$ & 4.1 & \pm & 3.1 & \\
\hline & & Negative & 2.7 & \pm & 5.7 & & 2.3 & \pm & 3.3 & & 2.5 & \pm & 2.9 & \\
\hline & Foreign & Positive & 0.2 & \pm & 0.7 & & 3.9 & \pm & 2.9 & $\# \# \#$ & 2.6 & \pm & 3.9 & \\
\hline & & Negative & 0.2 & \pm & 0.7 & & 0.1 & \pm & 0.3 & & 0.1 & \pm & 0.4 & \\
\hline \multirow[t]{4}{*}{ US papers } & Domestic & Positive & 12.7 & \pm & 30.6 & & 18.5 & \pm & 15.2 & $* * *$ & 14.2 & \pm & 15.6 & $*$ \\
\hline & & Negative & 10.2 & \pm & 30.0 & & 1.6 & \pm & 3.8 & & 9.4 & \pm & 13.0 & $\#$ \\
\hline & Foreign & Positive & 4.2 & \pm & 12.0 & & 3.9 & \pm & 11.5 & & 4.0 & \pm & 6.8 & \\
\hline & & Negative & 6.3 & \pm & 15.1 & & 2.4 & \pm & 7.0 & & 4.5 & \pm & 10.1 & \\
\hline \multicolumn{15}{|c|}{ Rationale for policy advocacy (\%) } \\
\hline \multirow[t]{4}{*}{ JP papers } & \multicolumn{2}{|c|}{ Health } & 7.2 & \pm & 7.9 & & 15.6 & \pm & 5.5 & $\# \# \#$ & 15.6 & \pm & 8.3 & \\
\hline & \multicolumn{2}{|c|}{ Economy } & 21.2 & \pm & 8.9 & & 24.8 & \pm & 9.6 & & 20.2 & \pm & 10.0 & \\
\hline & \multicolumn{2}{|c|}{ Balance } & 1.4 & \pm & 2.0 & & 2.4 & \pm & 2.4 & & 0.2 & \pm & 0.6 & \#\# \\
\hline & \multicolumn{2}{|c|}{ Acceptance } & 0.0 & \pm & 0.0 & & 0.5 & \pm & 0.8 & $\#$ & 0.6 & \pm & 1.1 & \\
\hline \multirow[t]{4}{*}{ US papers } & \multicolumn{2}{|c|}{ Health } & 38.1 & \pm & 43.1 & $*$ & 50.1 & \pm & 15.8 & $* * *$ & 57.3 & \pm & 25.4 & $* * *$ \\
\hline & \multicolumn{2}{|c|}{ Economy } & 33.4 & \pm & 29.3 & & 49.9 & \pm & 23.4 & $* * *$ & 49.8 & \pm & 23.7 & $* * *$ \\
\hline & \multicolumn{2}{|c|}{ Balance } & 6.1 & \pm & 11.3 & & 14.2 & \pm & 16.2 & $* * *$ & 24.7 & \pm & 30.3 & $*$ \\
\hline & \multicolumn{2}{|c|}{ Acceptance } & 20.2 & \pm & 31.3 & $*$ & 34.3 & \pm & 18.9 & $* * *$ & 42.2 & \pm & 19.2 & $* * *$ \\
\hline
\end{tabular}

Statistical significance for differences: same as described in Table 1 footnotes.

Proportions of the articles carrying advocacy statements and those of manifested/implied rationale for policy advocacy, when present.

ones.

The rationales for policy advocacy, either manifested or implied, are shown in Table 2. In Japan, economic reasons were cited in approximately $20 \%$ to $25 \%$ of the articles whereas health concerns were less frequently cited. The latter significantly increased, almost doubling in Periods 2 and 3 (15.6\%, 15.6\%) from Period 1 (7.2\%). In the US, health concerns and economic reasons were manifested almost equally in Period 1 (38.1\%, 33.4\%) and Period 2 (50.1\%, 49.9\%), while the former exceeded the latter in Period 3 (57.3\%, 49.8\%). A balance of competing policy objectives was rarely cited in articles in Japan: It increased in Period 2 (from 1.4\% to 2.4\%), and then decreased in Period $3(0.2 \%)$. Arguments for (rational) risk acceptance did not exist in Period 1 , but appeared in the later periods $(0.5 \%, 0.6 \%)$. In contrast, the US papers carried policy balance and risk acceptance more frequently, and both increased successively throughout the study period: The former increased from 6.1\% in Period 1 to $14.2 \%$ in Period 2 and $24.7 \%$ in Period 3 while risk acceptance increased from $20.2 \%$ in Period 1 to 34.3\% in Period 2 and 42.2\% in Period 3.

The results of the examination of individual articles using a multinominal logistic regression analysis are shown in Table 3. In the Japanese papers, the citation of health concerns indicated a greater likelihood that a given article carried advocacy for a stronger domestic policy rather than no advocacy (RRR $=3.38$ ). A discussion of the economy indicated a 4.69 times greater likelihood of stronger domestic policy advocacy and a 29.3 times greater likelihood of weaker advocacy. The discussion on policy balance and risk acceptance is associated with less positive advocacy (RRR $=0.34,0.35$, only the former is statistically significant) and with more negative advocacy (RRR $=4.06,6.94)$. Almost the same relationships were observed in the US papers, although they were less significant statistically. It was found that risk acceptance was associated with both stronger (positive) and weaker (negative) policy advocacy, although it was more indicative of the latter (RRR: 2.34 for positive, 5.92 for negative advocacy).

Health concerns and economic discussions were found to be associated with more positive foreign advocacy while policy balance was associated with less advocacy. Because of the limited number of articles that included foreign policy advocacy, either positive or negative, the analytic model on foreign policy advocacy for the US papers did not attain sufficient statistical power. 
Table 3. Relationship of advocacy orientation with rationale.

\begin{tabular}{|c|c|c|c|c|c|c|c|c|c|c|c|c|c|c|c|c|}
\hline & \multicolumn{8}{|c|}{ Domestic policy } & \multicolumn{8}{|c|}{ Foreign policy } \\
\hline & \multicolumn{4}{|c|}{ Positive } & \multicolumn{4}{|c|}{ Negative } & \multicolumn{4}{|c|}{ Positive } & \multicolumn{4}{|c|}{ Negative } \\
\hline & RRR & \pm & sd & $p$ & RRR & \pm & sd & $p$ & RRR & \pm & sd & $p$ & RRR & \pm & sd & $p$ \\
\hline \multicolumn{17}{|l|}{ JP papers } \\
\hline Health & 3.38 & \pm & 0.65 & $* * *$ & 0.65 & \pm & 0.17 & & 9.14 & \pm & 2.20 & $* * *$ & 0.31 & \pm & 0.44 & \\
\hline Economy & 4.69 & \pm & 0.93 & $* * *$ & 29.30 & \pm & 10.30 & $* * *$ & 4.00 & \pm & 1.01 & $* * *$ & 10.74 & \pm & 13.20 & \\
\hline Balance & 0.34 & \pm & 0.18 & $*$ & 4.06 & \pm & 1.53 & $* * *$ & 0.13 & \pm & 0.10 & $* *$ & 11.49 & \pm & 16.37 & \\
\hline Acceptance & 0.35 & \pm & 0.37 & & 6.94 & \pm & 3.56 & $* * *$ & 1.33 & \pm & 0.79 & & 0.00 & \pm & 0.04 & \\
\hline \multicolumn{17}{|l|}{ US papers } \\
\hline Health & 3.05 & \pm & 0.83 & $* * *$ & 0.94 & \pm & 0.55 & & 1.22 & \pm & 0.80 & & 1.01 & \pm & 0.66 & \\
\hline Economy & 0.83 & \pm & 0.20 & & 2.19 & \pm & 1.23 & & 0.68 & \pm & 0.42 & & 3.38 & \pm & 2.14 & \\
\hline Balance & 0.99 & \pm & 0.25 & & 1.10 & \pm & 0.30 & & 1.14 & \pm & 0.54 & & 1.34 & \pm & 0.31 & \\
\hline Acceptance & 2.34 & \pm & 0.54 & $* * *$ & 5.92 & \pm & 3.61 & $* *$ & 1.61 & \pm & 0.93 & & 1.41 & \pm & 0.86 & \\
\hline
\end{tabular}

Results of multinominal logistic regression analysis: Relative risk ratios (RRR) and their standard deviations for a given article to carry positive/negative advocacy (neutral orientation as baseline).

Statistical significance for difference between Japanese and US papers: *: $<0.05, * *:<0.01, * * *:<0.001$.

Overall statistical significance of each the analytical model (model p-value) $<0.001$, except for that on US foreign policy.

\section{Discussion}

Although the number of BSE-related newspaper articles increased in both the US and Japan-namely, the country in which BSE cases were newly found and its important trade counterpart, respectively-our study identified several differences in the issue's visibility (in terms of number of articles), the issue's faces (as represented by the dominant topic categories in which the issues were reported), and the policy advocacy accompanying the articles in the major dailies between the two countries studied.

\subsection{Issue Prominence and Geographic Focuses}

In many countries, issues related to BSE were widely reported in the media, especially in the early phases of the issue, when the threat to humans became scientifically known and infected cattle were found in the media's country. In Britain, for example, media reporting of BSE became conspicuous every time the risks of BSE to humans were made evident and threats to the public were suggested, such as in 1990, when the cross-species jumping of BSE was indicated, and in 1996, when the probable link between BSE and vCJD was announced (Miller, 1999). In Japan, the visibility of the BSE issue in the media rapidly increased when the first few BSE cattle cases were found in 2001. However, such visibility could not usually be sustained without the supply of new alarming (newsworthy) events, even though an issue-once remarkably highlighted-can have ensuing effects on the visibility and framing of that issue.

For both Japan and the US, in general, each country's counterpart was found to be frequently covered by the media, as a pair that was closely linked both socially and economically (Zhang \& Meadows, 2012). As expected, our study found that Japanese and US media conveyed news on BSE-related events occurring in the counterpart country. However, throughout the study periods, the number of BSE-related articles significantly differed between Japanese and US papers. This can be explained by the beef trade and commercial relationship between the two countries (Chang, Shoemaker, \& Brendlinger, 1987; Golan \& Wanta, 2003). As was reported on Canadian newspapers (Lewis \& Tyshenko, 2009), US newspapers carried significantly fewer articles on BSE than the Japanese ones.

Triggered by the BSE incidents in the US, the prominence of the BSE issue rapidly increased and was sustained for a while in Japan. Meanwhile, in the US, although the initial discovery of a BSE cow in the US on December 23, 2003, resulted in considerable media coverage, such coverage declined over a relatively short period. Japan is a major importer of US beef products, while the US is a major exporter of them to Japan (Obara, McConnell, \& Dyck, 2010). For the country importing the bulk of US beef products, this was a "new" threat to the health of consumers and also a serious threat to the economy connected to these products. For the US, the 
BSE issue became an important economic issue for the agricultural and food industry selling the beef products domestically and internationally as well as a health issue for domestic consumers (the case should be more or less similar except that the cattle-raising agricultural sector is relatively large in the US).

Socio-political factors, such as different levels of social, economic, and cultural importance of/interest in the issues as well as the government's handling of them and the influential social relationships within and around the organizations and individuals of mass media, could have resulted in this difference (Reese, 1991). The cattle industry is an economically large and politically powerful sector in the US, which undoubtedly had a stake in how the BSE issue was reported in the media and thus shaped its image in society. Since 1996, when the human transmission of BSE was announced in the UK, the meat and agriculture industries in the US have been concerned about the possibility that the government might take actions based on public pressure (responding to the irrational public food scare) rather than scientific evidence. These industries expended a great deal of effort conducting their own consumer research and exchanging opinions with the media, policymakers, and consumers, so that the government and consumers would base their decisions and behaviors on scientific data. These efforts might have resulted in less visible/sustained and hype-free reporting of BSE in the US.

Different styles of reporting (resulting in different article lengths with different frequencies on the same events) might also have contributed to this difference (Rowe, Frewer, \& Sjoberg, 2000). Japan's press tended to achieve a balance by presenting short, factual articles that cited no arguments whereas US papers did so by citing arguments from both sides. Consequently, in general, Japanese news reports tend to be much shorter (but possibly more visible) than US ones and were less likely to include the arguments involved in disputes or to cite sources (Budner \& Krauss, 1995).

\subsection{Domains and Faces of Newspaper Reports on the BSE Issue}

The framing of the issue, coupled with its visibility, helped set the agenda in the media and society. Frames refer to the way media present the issue and the way audiences interpret the information (Dimitrova \& Stroembaeck, 2005). The relative importance of different aspects of given issues as well as the possible impact on different social sectors (groups) can affect how the media cover the issues. Characteristics of events/issues and the social configuration around them are the determinants of their social impacts and the news coverage. Therefore, the tabulation of the domains of issue reporting reveals the social importance of each domain. Considering the dynamic nature of their relationships, media framing affects and reflects how people understand an issue and how society responds to the issue (Coleman \& McCombs, 2007). The case would expectedly be the same for BSE reporting.

In Britain, the faces of the issue reportedly changed over time, shifting from a non-human issue to a threat to humans and then a health crisis and an industrial scare with serious economic effects (Brookes, 1999). In Canada, the economic impacts of BSE were the primary focus of media coverage, whereas health risk concerns had little coverage (Boyd, Jardine, \& Driedger, 2009). As the beef cattle sector is important to the agricultural industry and the overall economy, the BSE issue emerged from an export ban on beef, thereby resulting in an economic crisis caused by that rather than a concern about food safety, even after a BSE cattle was reported in the country (Leiss \& Nicol, 2006).

Our study found that, in Japan, news articles in the commerce category comprised a large part of the related articles; in the US, the majority of articles were in the agriculture category. In Japan, many of the articles in the former category reported possible impacts on the beef retailers and food business; meanwhile, those in the agriculture category rapidly diminished in number as the national government implemented its BSE-testing and cattle-tracking programs and started recompensing cattle farms for their BSE-related economic loss. In the US, while health risks of BSE were not visibly reported, articles on the possible negative impact on agriculture (also linked with possible concerns about its negative impact on trade) were continuously remarkable. It was reported that, even after the detection of BSE in Canada and the US, confidence in the safety of beef products remained high in the US. Less remarkable media reporting of BSE in the US inferably reflected and affected that.

On the other hand, many articles in the trade category were published in both countries in Periods 2 and 3, after BSE-infected cattle was reported in the US and beef trade between the two countries was banned. It should be noted that, in Japan, trade articles were not as remarkable before Period 2, and BSE-related trade issues became a hot topic only thereafter, when the effects of BSE became real, the trade ban was a political agenda, and the policy measures to contain domestic BSE were discussed as being inseparable from-or at least closely con- 
nected with-those measures in the US. In the US, on the other hand, there were also many trade articles in Period 1 , prior to these developments. This could suggest that, even before the actual BSE incidents, concerns about the possible impact of BSE on trade were quite high in US media.

Economic losses linked to BSE in Japan were the result of domestic beef consumption changes, but in the cases of Canada and the US, the loss was due to closed export markets-a result of other countries' fear over contaminated beef products (Lewis \& Tyshenko, 2009). The former issue contributes to the increase in the reports on commerce and trade whereas the latter to the increase in those on agriculture and trade. The relative salience of each category addressed in our study corresponds well to the relative importance of different aspects/influence of the BSE issue in Japan and the US.

In addition to the importance of each domain to society, it should be noted that inertia in media reporting has been reported: The initial framing of an issue might determine its further coverage. In many countries, a set of major frames provided by the preceding reports in the initial period of BSE dominated media reporting of the issue over time (Boyd, Jardine, \& Driedger, 2009; Tourangeau \& Rainiski, 1988). In addition, in Japan and the US, initial (preceding) reporting styles on the BSE issues inferably influenced the subsequent ones. BSE remained largely an issue of human health and trade in Japan while it continued to be an issue of agriculture and trade in the US.

\subsection{Aversion and Acceptance of Health Risks}

Aversion and/or acceptance of certain health risks is a most important factor that affects and reflects the perception of the seriousness and nature of health risks among the public, industry, and policymakers as well as the choice of policies against them. In policy analysis, problems are analytical constructs; in politics they are political constructs (Short, 1984). Defining the problem answers questions concerning the decision to be made, the ends to be achieved, and the means that can be chosen (Dery, 2000; Schon, 1983). Here, the way a public health issue is framed in the media is closely linked to the solution to the problem that the frame implies (Wallack et al., 1993). In one way or another, controlling the problem definition can be an important and potent tactic of issues management (Stone, 1988). Therefore, mass media sometimes becomes a potential playground for those who have economic, moral, political, and scientific stakes in given issues, all the more because how journalists frame a given issue can be maneuvered by them (Shoemaker \& Reese, 1996; Tuchman, 1978).

In health risk management, the importance attached to the issue and the appropriate methods of management are topics of interest. Campaigning is one conspicuous form of the concerted actions to promote a certain view/frame to affect the course of these discussions. Risk campaigning in mass media denotes the conscious and systematic promotion of particular causes and issues (Richardson, 2006). In the past, in addition to the media itself, social interest groups, motivated individuals, and the government and state are not only responsible to media campaigning, but are also important risk campaigners in their own right, conducted primarily through the media. Campaigning often focuses attention on only particular possible harms and has the tendency for absolute intolerance of risk as opposed to mitigation and balancing against costs and benefits; thus, it is likely to be alarming (Carducci, 2011; Douglas \& Wildavsky, 1982). It might be morally charged, science minded, or safety oriented (Goldsworthy, 2006). However, campaigning does not always take a risk-amplifying form; newspapers have also campaigned to contest risk. By presenting relative, instead of absolute, risks of a hazard or event, the media are able to magnify the public's perception of the risk (Abbassi, 1998).

In the UK, some media reportedly took on a clear campaigning role in BSE reporting (Eldridge \& Reilly, 2003). The perceived mismanagement of BSE provided a clear focus for newspaper campaigning, attacking the denial of the downplaying of risk. The politics of risk identification were reconfigured: In the past, those promoting new concerns without rigorous substantiation were open to the charge of irresponsibility, creating unnecessary psychological, social, and economic costs for no clear public benefit. After the emergence of BSE, voicing risk concerns could be cast as responsible alerting of the public to impending dangers either neglected or denied by authorities (Burgess, 2010). In addition, in Canada, rally behavior to support Canadian beef farmers played a risk-attenuating role in mass media and society after the discovery of BSE (Lewis \& Tyshenko, 2009).

As in Canada, associations representing agricultural producers in the US are usually powerful lobby groups with influence over food safety regulations (Nestle, 2003). The National Cattlemen's Beef Association began market research with US consumers in 1996, including focus groups, quantitative tracking surveys, and BSE media coverage monitoring. Immediately upon the announcement of the first US BSE case, it endeavored to 
communicate a unified message to the media (Hendrix \& Hayes, 2007). Its strategy was to aggressively communicate the actions of the US government to ensure that BSE was not a health risk; establish its website as a key source of information for industry, media, beef marketers, governments, and consumers; and work diligently with other players to present a unified and science-based message to all audiences, insisting that the US government keep the process transparent and science driven while counteracting misinformation by ensuring that accurate information was broadly available. The attenuation of BSE issue in the US (media) could be due to the newspaper campaign introduced and implemented by the beef industry.

Meanwhile, in Japan, in the early days when BSE became known overseas and when BSE was found among its own cattle, its potential health risk was highlighted, and the elimination of BSE-rather than the reduction and acceptance of the risk-was discussed as desirable in the media. By not questioning their rationality, focusing on the BSE risk without drawing comparisons to other health risks and ignoring the balancing of competing policy objectives, the Japanese mass media implicitly and explicitly upheld "zero risk" as a policy goal, which was not always endorsed by science. Domestic beef producers tried to maintain the sales of their products by differentiating them as "safe (r)" national brands. The promotion of the idea of rational risk acceptance was not the end of their marketing efforts.

\subsection{Policy Advocacy}

Closely related with aversion and acceptance of a risk is the media advocacy of policy referring to judgmental statements on the policies already in place and/or calls for stronger or weaker alternatives. Such statements would help shape public perception about what was left to be done and who was responsible. Therefore, the slants (valence) of newspaper articles (advocacy) can also be interpreted as the policy appraisal by the media. The media thus plays a pivotal role in setting goals, assigning responsibility, and assessing the efforts of governments (Majone, 1989). For example, the public might be perfectly content with the ongoing policies if they are persuaded to accept certain levels of risk (e.g., a small risk of BSE incidence, which poses quite a minimal threat to humans) or if they regard the policy efforts to be well in place and the incidence beyond the control capacity of the government/industry. On the other hand, when the policy target (therefore, the responsibility of the government) is zero risk (i.e., the total elimination of its risk), the discovery of BSE cattle can easily be interpreted as a policy failure, which might invoke calls for stronger (more effective) policies.

In our study, a small portion of BSE articles in the Japanese newspapers called for stronger rather than weaker domestic policies; an even smaller part of them called for stronger safety measures on the US side. Media thus appeared to be more or less content with the domestic safety measures already in place at the time. The latter, most of which called for US actions in accordance with the Japanese standards, became more eminent after the BSE cases were found in the US. In the meantime, US media expressed advocacy arguments more frequently than the Japanese media, calling for stronger domestic policies, rather than weaker ones; the former became more visible than the latter after BSE incidents occurred in the US. In both contexts, arguments for stronger policies were likely to be made for health concerns, while those for weaker ones were for economy and trade and were linked with the rational acceptance of risks.

In Japan in 1995, the MAFF issued only non-binding and far from comprehensive guidance to farmers on what products they should avoid. Consequently, hundreds of tons of MBM were imported from Europe in the form of fish food. When a BSE cattle was discovered in Japan in 2001, the loose regulations were blamed, arguing that they were based on foolish optimism or on the government's decision to put industry interests before those of consumers (Watts, 2001). The media called for tighter regulatory actions, urging the government to ban MBM imports. Later, when the first few cases of BSE cattle were discovered, the government introduced the BSE-testing and cattle-tracking programs. As the government reassured the public that there should be no risk, the government was inclined to continue pursuing the zero-risk target. The media, once having approved that, continued to call for stronger policy. Any compromise had to be carefully presented to the public.

Under these circumstances, any BSE risks associated with trades, not inherent to a given country, are easily conceived as those which are man-made, (otherwise) controllable, and introduced by the mismanagement of risks on either side or both sides of trading partners; consequently, they are likely to incur public outrage (Sandman, 1993), as exemplified by the UK, French, and German cases in which the national governments and their policies were vehemently blamed when the media regarded the BSE risks to be the result of human mismanagement (Feindt \& Kleinschmit, 2011; Goffman, 1974; Washer, 2005). In Japan, politicians and bureaucrats 
were wary of this failure. They tried to introduce all possible measures to contain BSE (not always deemed necessary by scientific evidence nor considered cost-effective by rational calculations) while simultaneously conveying as much information to the public. With all the possible measures in place and the total ban on beef imports from the US, there were rather rare calls for stronger domestic policies in the media. However, calls for stronger policies on the US side increased when the specified risk materials, which should have been removed according to the US-Japan trade agreement, were found to have contaminated the beef products imported from the US.

In the US, on the other hand, a series of federal and state policies, along with the well-planned communication tactics by the government and the industry, successfully indoctrinated the media, policymakers, and the public to the view that the management of BSE-related risks should be science-based, cost-effective efforts; such policies continued to persuade them that the risks were under control (to an acceptable level). A similar situation occurred in Canada: The majority of Canadian articles conveyed that the government acted properly, keeping the matters under control and the public informed. At the same time, messages from the beef industry also had a notable impact on helping consumers respond to the BSE outbreak (Wansink, 2004). However, when BSE cattle were actually discovered, calls for stronger policies increased temporarily in the US, although calls for weaker policies also increased to a lesser extent.

The finding that a larger proportion of articles carried policy advocacy in US media than in Japanese media was consistent with the general characteristics of newspapers in both countries: Japanese news reports tended to be much shorter than US ones and were less likely to include the arguments involved in disputes or to cite sources (Budner \& Krauss, 1995). It was also noted that Japan's press tended to achieve balance by presenting short, factual articles that cited no arguments whereas US papers did so by citing arguments from both sides.

\subsection{Opportunities for Policy Improvement and Coordination}

Health and safety regulations can be understood as expressions of a nation's political and social values that are inextricably associated with the social configurations and processes around the issue (Douglas \& Wildavsky, 1982). When a difference exists in the level of risk acceptance, philosophy of safety regulation, and the policy and programs, safety regulations are sometimes disputed as trade barriers by those with economic stakes (Anders \& Caswell, 2009; Roberts \& Unnevehr, 2005). Here, the discovery of difference in policy decisions between two countries and media reports discussing them can serve-and in reality have served-as valuable opportunities for the critical (re-)appraisal of the policies on both sides, either under consideration or in place, for both countries (Hagen, 1997).

In Japan, sustained attention on the BSE issue as a health threat reflected the dominant media framing adopted by its media. Reassurance policy and programs, such as the BSE testing of all cattle without age limits and the total ban on beef products from the US-neither of which were necessarily based on the judgments of scientific evidence and regulatory efficiency-were not squarely intended to promote the public's understanding and rational acceptance of BSE-related health risks. Meanwhile, in the US, the effective and efficient risk management and the rational acceptance of BSE risks were pursued. Thus, safety policies in Japan and the US had a factor intrinsically incompatible with each other. Japan's legal traditions, which assign the responsibility of consumer protection more to the government than to the producers and sellers by product liability law, might also have contributed to the risk-averse attitudes of the government (Vogel, 1992). Furthermore, in addition to consumer groups, producer groups in Japan sometimes attempted to take advantage of the public's concern about health and safety in order to generate political support for continued restriction on imports (Edelman, 1988). "National brands" were used as secondary symbols linking the issue to certain policy action, calling for and justifying nationalistic (protective) regulatory actions.

However, trade disputes and the media reports discussing the differences in policy certainly helped reappraise and change the domestic policies in Japan as well as practically solve the policy incompatibility between the two countries. The relationship of the media agenda with political agenda and with administrative policy actions was sometimes confirmed (Sato, 2003). US policies on BSE, as reported in the media, served as reference points for the politicians, bureaucrats, agricultural and other business interests, and public in Japan who were discussing BSE-related safety measures. In the US, they provided opportunities to correct the failures and defects of a safety program for the export of beef products as well as for those to be domestically consumed (R-CALF USA, 2005). 


\section{Conclusion}

Media reports on health risks reflect the social implications of those risks and, therefore, the configuration of social interests and their powers in which they operate (Davidson \& Bogdan, 2010). Discussion in the media about the acceptance and aversion of health risks and what policy measures are desirable are also associated with them. Media are thus a key arena where policy choices and responsibilities with regard to food system governance are negotiated (Kepplinger, 2002). Consequently, the visibility and faces of certain health issues in the media differ between countries, as in the case of the policies themselves. However, when there are differences in risk perception and management, those differences, as reported by the media, could serve as vehicles for reappraising the existing policies and help understand what factors are the key determinants for policies on both sides of trading partners which might have disputes on the safety measures and trade barriers.

\section{Acknowledgements}

This study was supported by the Grants-in-Aid for Scientific Research "Risk communications in mass media during heath crises: An international comparative study (2012-2013)," granted by Japan Society for the Promotion of Science to Hajime Sato. It was also supported by a research grant "Strategic communications of health risks (2010-2011)” awarded to Hajime Sato by the Alliance for Global Sustainability at the University of Tokyo.

\section{Declaration on Conflicts of Interests}

The authors declare that there are no existing conflicts of interest.

\section{References}

Abbassi, K. (1998). Headlines: More Perilous than Pills? British Medical Journal, 316, 82. http://dx.doi.org/10.1136/bmj.316.7124.82

Anders, S. M., \& Caswell, J. A. (2009). Standards as Barriers versus Standards as Catalysts: Assessing the Impact of HACCP Implementation on US Seafood Imports. American Journal of Agricultural Economics, 91, 310-321. http://dx.doi.org/10.1111/j.1467-8276.2008.01239.x

Boyd, A. D., Jardine, C. G., \& Driedger, S. M. (2009). Canadian Media Representations of Mad Cow Disease. Journal of Toxicology and Environmental Health, Part A, 72, 1096-1105. http://dx.doi.org/10.1080/15287390903084629

Brookes, R. (1999). Newspapers and National Identity: The BSE/CJD Crisis and the British Press. Media, Culture and Society, 21, 247-263. http://dx.doi.org/10.1177/016344399021002007

Budne, S., \& Krauss, E. S. (1995). Newspaper Coverage of US-Japan Frictions: Balance and Objectivity. Asian Survey, 35, 336-356. http://dx.doi.org/10.2307/2645799

Burgess, A. (2010). Media Risk Campaigning in the UK: From Mobile Phones to Baby P. Journal of Risk Research, 13, 5972. http://dx.doi.org/10.1080/13669870903136035

Campbell, R. G., \& Sato, H. (2009). Examination of a Global Prohibition Regime: A Comparative Study of Japanese and US Newspapers on the Issue of Tobacco Regulation. The International Communication Gazette, 71, 161-179. http://dx.doi.org/10.1177/1748048508100911

Campbell, R., \& Sato, H. (2010). Policy and Politics of BSE in the United States. In H. Sato (Ed.), Management of Health Risks from Environment and Food: Policy and Politics of Health Risk Management in Five Countries-Asbestos and BSE (pp. 317-338). Netherlands: Springer.

Carducci, A., Alfani, S., Sassi, M., Cinini, A., \& Calamusa, A. (2011). Mass Media Health Information: Quantitative and Qualitative Analysis of Daily Press Coverage and Its Relation with Public Perceptions. Patient Education and Counseling, 82, 475-478. http://dx.doi.org/10.1177/1748048508100911

Chang, T. K., Shoemaker, P. J., \& Brendlinger, N. (1987). Determinants of International News Coverage in the US Media. Communication Research, 14, 396-414. http://dx.doi.org/10.1177/009365087014004002

Chapman, S., \& Lupton, D. (1994). The Fight for Public Health: Principles and Practice of Media Advocacy. London: BMJ Publishing Group.

Coleman, R., \& McCombs, M. (2007). The Young and Agenda-Less? Exploring Age-Related Differences in Agenda Setting on the Youngest Generation, Baby Boomers, and the Civic Generation. Journalism and Mass Communications Quarterly, 84, 495-508. http://dx.doi.org/10.1177/107769900708400306

Cotte, S., \& Ulrich, B. (1998). Risk Society and the Media. European Journal of Communication, 13, 5-32. 
Davidson, D. J., \& Bogdan, E. (2010). Reflexive Modernization at the Source: Local Media Coverage of Bovine Spongiform Encephalopathy in Rural Alberta. Canadian Review of Sociology, 47, 359-380.

http://dx.doi.org/10.1111/j.1755-618X.2010.01242.x

Dery, D. (2000). Agenda Setting and Problem Definition. Policy Studies, 21, 37-47. http://dx.doi.org/10.1080/014428700114008

Dimitrova, D. V., \& Stroembaeck, J. (2005). Mission Accomplished? Framing of the Iraq War in the Elite Newspapers in Sweden and the United States. Gazette, 67, 399-417. http://dx.doi.org/10.1177/0016549205056050

Douglas, M., \& Wildavsky, A. (1982). Risk and Culture. Berkeley, CA: University of California Press.

Edelman, P. (1988). Japanese Product Standards as Non-Tariff Trade Barriers: When Regulatory Policy Becomes a Trade Issue. Stanford Journal of International Law, 24, 389-446.

Eldridge, J., \& Reilly, J. (2003). Risk and Relativity: BSE and the British Media. In N. Pidgeon, R. Kasperson, \& P. Slovic (Eds.), The Social Amplification of Risk (pp. 138-155). Cambridge: Cambridge University Press. http://dx.doi.org/10.1017/CBO9780511550461.007

Feindt, P. H., \& Kleinschmit, D. (2011). The BSE Crisis in German Newspapers: Reframing Responsibility. Science as Culture, 20, 183-208. http://dx.doi.org/10.1080/09505431.2011.563569

Goffman, E. (1974). Frame Analysis: An Essay on the Organization of Experience. Cambridge, MA: Harvard University Press.

Golan, G., \& Wanta, W. (2003). International Elections on the US Network News: An Examination of Factors Affecting Newsworthiness. Gazette, 65, 25, 40.

Goldsworthy, S. (2006). English Nonconformity and the Pioneering of the Modern Newspaper Campaign. Journalism Studies, 7, 387-402. http://dx.doi.org/10.1080/14616700600680690

Goodel, R. (1987). The Role of Mass Media in Scientific Controversy. In T. Englehardt, \& A. Caplan (Eds.), Scientific Controversies: Case Studies in the Resolution and Closure of Disputes in Science and Technology (pp. 585-598). Cambridge: Cambridge University Press. http://dx.doi.org/10.1017/CBO9780511628719.028

Hagen, I. (1997). Communicating to an Ideal Audience: News and the Notion of the Informed Citizen. Political Communication, 14, 405-419. http://dx.doi.org/10.1080/105846097199209

Hendrix, J. A., \& Hayes, D. C. (2007). Emergency Public Relations Cases: Protecting Consumer Confidence in US Beef: A Success Story. In J. A. Hendrix, \& D. C. Hayes (Eds.), Public Relations Cases: Seventh Edition (pp. 378-386). Belmont: Thomson Wadsworth.

Leiss, W., \& Nicol, A. N. (2006). A Tale of Two Food Risks: BSE and Farmed Salmon in Canada. Journal of Risk Research, 9, 891-910. http://dx.doi.org/10.1080/13669870600924584

Kepplinger, H. M. (2002). Mediatization of Politics: Theory and Data. Journal of Communication, 52, 972-986. http://dx.doi.org/10.1111/j.1460-2466.2002.tb02584.x

Kim, S., Scheufele, D. A., \& Shanahan, J. (2002). Think About it This Way: Attribute Agenda-Setting Function of the Press and the Public's Evaluation of a Local Issue. Journalism and Mass Communication Quarterly, 79, 7-25. http://dx.doi.org/10.1177/107769900207900102

Kleinschmit, D., \& Krott, M. (2008). The Media in Forestry: Government, Governance and Social Visibility. In T. Sikor (Ed.), Public and Private in Natural Resource Governance: A False Dichotomy (pp. 127-141). London: Earthscan.

Lewis, R. E., \& Tyshenko, M. G. (2009). The Impact of Social Amplification and Attenuation of Risk and the Public Reaction to Mad Cow Disease in Canada. Risk Analysis, 29, 714-728. http://dx.doi.org/10.1111/j.1539-6924.2008.01188.x

Majone, G. (1989). Evidence, Argument, and Persuasion in the Policy Process. New Haven, CT: Yale University Press.

Miles, M. B., \& Huberman, A. M. (1994). Qualitative Data Analysis: An Expanded Sourcebook. London: Sage.

Miller, D. (1999). Risk, Science and Policy: Definitional Struggles, Information Management, the Media and BSE. Social Science and Medicine, 29, 1239-1255. http://dx.doi.org/10.1016/S0277-9536(99)00163-X

Nestle, M. (2003). Safe Food: Bacteria, Biotechnology, and Bioterrorism. Berkeley, CA: University of California Press.

Obara, K., McConnell, M., \& Dyck, J. (2010). Japan's Beef Market: A Report from the Economic Research Service. LDP-M-194-01. Washington, DC: United States Department of Agriculture.

R-CALF USA (2005). http://www.r-calfusa.com/BSE/050201-PositionBriefonSRMs.pdf

Reese, S. D. (1991). Setting the Media’s Agenda: A Power Balance Perspective. In J. A. Anderson (Ed.), Communication Yearbook 14 (pp. 309-340). Thousand Oaks, CA: Sage Publications, Inc.

Richardson, J. (2006). Analysing Newspapers: An Approach from Critical Discourse Analysis. London: Palgrave Macmillan.

Roberts, D., \& Unnevehr, L. (2005). Resolving Trade Disputes Arising from Trends in Food Safety Regulation: The Role of the Multilateral Governance Framework. World Trade Review, 4, 469-497.

http://dx.doi.org/10.1017/S1474745605002466 
Rowe, G., Frewer, L., \& Sjoberg, L. (2000). Newspaper Reporting of Hazards in the UK and Sweden. Public Understanding of Science, 9, 59-78. http://dx.doi.org/10.1088/0963-6625/9/1/304

Sandman, P. M. (1999). Responding to Community Outrage: Strategies for Effective Risk Communication. Fairfax, VA: American Industrial Hygiene Association.

Sato, H. (2003). Agenda Setting for Smoking Control in Japan, 1945-1990: Influence of the Mass Media on National Health Policy Making. Journal of Health Communication, 8, 23-40. http://dx.doi.org/10.1080/10810730305731

Sato, H. (2010). Policy and Politics of BSE-Related Human Disease Prevention in Japan: In Pursuit of Food Safety and Public Reassurance. In H. Sato (Ed.), Management of Health Risks from Environment and Food: Policy and Politics of Health Risk Management in Five Countries-Asbestos and BSE (pp. 183-220). Berlin: Springer. http://dx.doi.org/10.1007/978-90-481-3028-3

Schon, D. A. (1983). The Reflective Practitioner. New York: Basic Books.

Shoemaker, P. J., \& Reese, S. D. (1996). Mediating the Message (2nd ed.). White Plains, NY: Longman.

Short, J. F. (1984). The Social Fabric at Risk: Toward the Social Transformation of Risk Analysis. American Sociological Review, 49, 711-725. http://dx.doi.org/10.2307/2095526

Smith, K. C., Terry-McElrath, Y., Wakefield, M., \& Durrant, R. (2005). Media Advocacy and Newspaper Coverage of Tobacco Issues: A Comparative Analysis of 1 Year's Print News in the United States and Australia. Nicotine and Tobacco Research, 7, 289-299. http://dx.doi.org/10.1080/14622200500056291

Stone, D. A. (1988). Policy Paradox and Political Reason. New York: Harper Collins.

Tourangeau, R., \& Rainiski, K. A. (1988). Cognitive Processes Underlying Context Effects in Attitude Measurement. Psychological Bulletin, 103, 299-314. http://dx.doi.org/10.1037/0033-2909.103.3.299

Treiman, D. J. (2009). Quantitative Data Analysis: Doing Social Research to Test Ideas. San Francisco, CA: Jossey-Bass.

Tuchman, G. (1978). Making News: A Study in the Construction of Reality. New York: Free Press.

US International Trade Commission. (2008). Global Beef Trade: Effects of Animal Health, Sanitary, Food Safety, and other Measures on US Beef Exports. Investigation 332-488, USITC Publication 4033, Washington, DC: US International Trade Commission.

Vogel, D. (1992). Consumer Protection and Protectionalism in Japan. Journal of Japanese Studies, 18, 119-154. http://dx.doi.org/10.2307/132709

Wallack, L., \& Dorfman, L. (1996). Media Advocacy: A Strategy for Advancing Policy and Promoting Health. Health Education Quarterly, 23, 293-317. http://dx.doi.org/10.1177/109019819602300303

Wallack, L., Dorfman, L., Jernigan, D., \& Themba, M. (1993). Media Advocacy and Public Health: Power for Prevention. Newbury Park, CA: Sage.

Washer, P. (2005). Representations of Mad Cow Disease. Social Science and Medicine, 62, 457-466. http://dx.doi.org/10.1016/j.socscimed.2005.06.001

Wansink, B. (2004). Consumer Reactions to Food Safety Crisis. Advances in Food and Nutrition Research, 48, 103-150. http://dx.doi.org/10.1016/S1043-4526(04)48002-4

Watts, J. (2001). Japan’s Government Tries to Allay BSE Fears. The Lancet, 358, 2057. http://dx.doi.org/10.1016/S0140-6736(01)07150-1

Zhang, C., \& Meadows, C. W. (2012). International Coverage, Foreign Policy, and National Image: Exploring the Complexities of Media Coverage, Public Opinion, and Presidential Agenda. International Journal of Communication, 6, 76-95. 